\title{
Utilização da análise de coliformes como indicativo de sanidade dos mexilhões Perna perna (Linnaeus, 1758) cultivados na ilha Guaíba, Rio de Janeiro
}

\section{Coliform enumeration used as a sanitation indicative factor from Perna perna (Linnaeus, 1758) mussels cultivated in Guaíba Island, Rio de Janeiro}

\begin{abstract}
Milena Marcela Domingues Pereira, ${ }^{*}$ Vanessa de Magalhães Ferreira, ${ }^{*}$ ** Rômulo Cardoso Valadão, * Gesilene Mendonça de Oliveira, ${ }^{*}$ Tatiani Abreu de Alencar, ${ }^{*}$ Ana Lúcia Medeiros dos Santos Ribeiro, ${ }^{*}$ Pedro Paulo de Oliveira Silva, ${ }^{*}$ Celso Guimarães Barbosa***
\end{abstract}

\begin{abstract}
Resumo
O mexilhão Perna perna é a espécie de molusco bivalve predominante nas fazendas marinhas de todo o Brasil. O monitoramento bacteriológico de moluscos comercializados deve ser realizado frequentemente devido aos bivalves serem capazes de bioacumular patógenos presentes na coluna d'água onde crescem. Os mexilhões são animais filtradores utilizados para alimentação humana. Portanto, a contaminação ambiental afeta tanto a sanidade do animal quando a Saúde Coletiva. Os níveis de coliformes totais e termotolerantes presentes nos moluscos foram determinados através da técnica do Número Mais Provável (NMP) de abril de 2007 a março de 2008. Os níveis de coliformes totais nos tecidos dos mexilhões variaram de 0,27 a 160,94 NMP.g-1 ${ }^{-1}$ enquanto os termotolerantes estiveram entre < 0,18 e 35,73 NMP.g-1. É possível que os coliformes presentes em tais concentrações sejam capazes de tornar os moluscos mais susceptíveis a fatores de estresse durante sua comercialização. Análises específicas para cada organismo patogênico e substâncias tóxicas precisam ser desenvolvidas.
\end{abstract}

Palavras-chave: malacocultura, coliformes totais e termotolerantes, sanidade animal, Saúde Coletiva.

\begin{abstract}
The most predominant species of bivalve mollusc cultivated in Brazil's marine farms is the brown mussel Perna perna. Bacteriological monitoring of commercialized shellfish has to be carried out frequently due to their ability to concentrate pathogens from the water column where they grow up. Mussels are filter-feeding animals used in human diet. Therefore, environmental contamination not only does affect their own sanitation, but also the public health. Total and fecal coliform levels present in shellfish were determined by the Most Probable Number (MPN) technique from April 2007 to March 2008. Total and thermotolerant coliform mean concentrations varied from 0,27 to 160,94 NMP.g ${ }^{-1}$ and $<0,18$ to 35,73 NMP.g ${ }^{-1}$, respectively. There is a probability that such coliform concentrations are likely to turn mussels more susceptible to stress factors during their commercialization. Specific analyses for each pathogen and toxic substances are still to be carried out.
\end{abstract}

Keywords: mollusc culture, total and fecal coliforms, animal sanitation, Public Health.

\section{Introdução}

Desde os primórdios da maricultura no Rio de Janeiro, o mexilhão Perna perna vem sendo uma das três espécies de moluscos bivalves mais cultivadas no estado. A produção nacional de mexilhões saltou de 190 para 11.760 toneladas entre os anos de 1990 e 2000, o que contribuiu para o Brasil se tornar o segundo maior produtor em volume de produção da aquicultura latino-americana, sendo superado apenas pelo Chile (FAO, 2006; FAO, 2008; Ibama, 2008; Ferreira, 2009).

O município de Mangaratiba é um dos polos mais promissores para o desenvolvimento da mitilicultura fluminense (BRASIL, 2007), principalmente devido à grande disponibilidade de nutrientes presentes em suas águas para 0 cres-

\footnotetext{
* Laboratório de Toxinas Marinhas, Departamento de Tecnologia de Alimentos, Universidade Federal Rural do Rio de Janeiro. Rodovia BR 465 Km 7 Campus Universitário, Seropédica, RJ, CEP: 23890-000. A quem enviar a correspondência. E-mail: milena.toxmar@gmail.com

** Faculdade de Oceanografia, Universidade Estadual do Rio de Janeiro. Av. São Francisco Xavier, 524, 4 andar, sala 4023, Maracanã, RJ, CEP 20550-013.

*** Departamento de Matemática, Instituto de Ciências Exatas, UFRRJ.
} 
cimento dos animais. Moluscos bivalves são animais que se alimentam por filtração, motivo pelo qual bioacumulam patógenos em níveis muito mais elevados do que aqueles presentes nas águas em que são criados (Leal; Franco, 2008). Sendo assim, a contaminação bacteriológica de seus tecidos está intrinsecamente relacionada com as condições do ambiente no qual o animal se desenvolveu durante o seu ciclo vital (Lee; Morgan, 2003; Pereira, 2008).

Os moluscos são sensíveis a contaminantes e seu sistema imunológico funciona como agente de alerta a estresses ambientais, alterando o seu estado de bem-estar (Canesi et al., 2001; Akaishi, 2007). A colimetria dos moluscos marinhos vem sendo tradicionalmente utilizada como principal indicador de características de qualidade biótica das áreas de cultivo e da sanidade desses animais (Silva-Souza, 2006; Vieira et al. 2007). Porém, os efeitos da contaminação bacteriológica sobre os moluscos ainda são pouco conhecidos e difundidos, além de serem específicos para cada espécie de molusco e região de produção. Logo, precisam ser analisados dentro da realidade local de cada ponto de cultivo (Lee; Morgan, 2003). O conhecimento sobre os organismos patogênicos, seu modo de contaminação e ação sobre os moluscos e a disseminação de informações para a prática de controle e prevenção de enfermidades irá se refletir na qualidade destes como alimento quando comercializados (Silva-Souza, 2006; Suplicy, 2007; Ferreira, 2009).

Países do hemisfério norte têm produzido muito conhecimento científico sobre o assunto nos últimos 40 anos; entretanto, é necessário se ter cautela ao utilizar estes dados para a realidade brasileira: as condições bióticas e abióticas de nosso litoral são distintas, além de se cultivar espécies diferentes daquelas encontradas na Europa e nos Estados Unidos, como é o caso das espécies nativas, a vieira Nodipecten nodosus e o mexilhão Perna perna (Silva-Souza, 2006; Magalhães et al., 2007; Suplicy, 2007).

Apesar da fazenda marinha localizada na ilha Guaíba funcionar comercialmente desde o ano de 2005, dados que indicassem a sanidade dos mexilhões cultivados no local eram ainda inexistentes (informação verbal). ${ }^{1}$

Do ponto de vista da sanidade dos bivalves marinhos, diversos autores relatam surtos de enfermidades ocorridos como consequência da disseminação de patógenos. Dentre as doenças de origem bacteriana, a vibriose parece ser uma das mais frequentes infecções ocorridas em animais marinhos, contudo, apesar das bactérias do gênero Vibrio serem naturais do ambiente marinho, parece haver alguma correlação entre sua ocorrência e a contaminação de origem fecal (Vieira et al., 2007). A frequência de parasitismo por bucefalídeos, principal enfermidade que acomete mexilhões, também pode estar relacionada com a exposição dos animais à água contaminada por esgoto (Moles; Hale, 2003) e à presença de coliformes termotolerantes (Galvão et al., 2006). Henriques et al. (2003, 2006, 2007) discutiram ainda a possível influência da contaminação por coliformes no tempo de resistência do mexilhão à exposição ao ar, baixas salinidades e altas temperaturas.

\footnotetext{
${ }^{1}$ Comunicação feita por M. L. SOUZA, presidente da Associação de Maricultores de Mangaratiba em 2007.
}

O presente estudo teve como objetivo detectar os níveis de coliformes totais e termotolerantes presentes nos mexilhões cultivados na ilha Guaíba (RJ), discutindo sua relação com a sanidade do animal e a utilização desta ferramenta como indicativa da qualidade dos moluscos para a Saúde Coletiva.

\section{Material e métodos}

\section{Área de estudos}

A fazenda marinha onde o experimento foi instalado localizase na Ponta da Passagem, em frente à ilha Guaíba, Baía de Sepetiba, município de Mangaratiba, litoral sul do estado do Rio de Janeiro. As coordenadas geográficas do cultivo são: $22^{\circ} 59^{\prime} 49^{\prime \prime S}$ e $44^{\circ} 02^{\prime} 14^{\prime \prime}$.

\section{Instalação do cultivo experimental}

Nos meses de março e outubro de 2007, foram confeccionadas um total de 70 cordas mexilhoneiras, com 100 animais cada uma, pela equipe do Laboratório de Toxinas Marinhas (ToxMar) da Universidade Federal Rural do Rio de Janeiro, com a colaboração da Associação de Maricultores (AMAR) e da Prefeitura Municipal de Mangaratiba. Os mexilhões foram fornecidos pela AMAR e extraídos dos cabos da própria estrutura de cultivo, sendo desta maneira oriundos do mesmo local onde posteriormente as cordas foram instaladas em sistema de cultivo suspenso chamado espinhel ou "long-line" para a engorda dos animais. O suprimento de alimento, microalgas e material orgânico particulado foi fornecido pelo ambiente marinho.

\section{Amostragem}

Foram realizadas 10 coletas durante o período de abril de 2007 a março de 2008 e em cada qual foram extraídas duas amostras a partir de duas cordas de cultivo. Para compor cada amostra, 12 animais adultos (maiores que $60 \mathrm{~mm}$ ) eram retirados de uma única corda mexilhoneira, ao acaso e ao longo de toda a corda. Foram processadas 20 amostras, totalizando 240 espécimes analisados. Para as análises realizadas entre os meses de abril e setembro de 2007, os indivíduos foram coletados a partir das cordas confeccionadas em março. Já para as análises realizadas de novembro de 2007 a março de 2008, as cordas foram montadas em outubro. Questões operacionais do cultivo impossibilitaram que todos os animais analisados durante o período fossem provenientes de uma única semeadura.

\section{Coleta e transporte das amostras}

Em cada coleta, depois de removidos os epibiontes e sujidades, os mexilhões tiveram suas valvas lavadas e escovadas, utilizando-se a água do mar do próprio cultivo. Cada amostra foi acondicionada em bolsa de polietileno $\left(\right.$ Ziploc $\left.^{\circledR}\right)$, seguindo até o Laboratório de Microbiologia de Alimentos (IT/UFRRJ) em caixa isotérmica refrigerada com gelo reciclável. Todas as amostras foram analisadas em até três horas a partir da coleta. 


\section{Determinação do Número Mais Provável (NMP) de organismos indicadores}

Coliformes totais e termotolerantes foram enumerados utilizando-se o método do NMP, inoculando-se três séries de cinco tubos com 10 e $1 \mathrm{~mL}$ da diluição $10^{-1}$ e $1 \mathrm{~mL}$ da diluição $10^{-2}$, conforme recomendações estabelecidas pela Instrução Normativa nํ 62 do Ministério da Agricultura, Pecuária e Abastecimento - MAPA (BRASIL, 2003).

\section{Análise estatística}

A análise dos dados da colimetria, transformados previamente em raiz quadrada, foi realizada pela análise de variância (ANOVA), complementada pelo teste de Tukey para comparação de médias, ambos ao nível de $5 \%$ de significância (Vieira, 2006).

\section{Resultados e discussão}

Os valores médios de coliformes totais encontrados nas amostras de mexilhões analisadas em duplicatas ficaram entre 0,27 e 160,94 NMP.g ${ }^{-1}$ de massa corpórea do molusco, com média anual de 24,50 NMP.g ${ }^{-1}$ Os valores para os termotolerantes estiveram entre $<0,18$ e 35,73 NMP.g ${ }^{-1}$ e a média foi de 4,63 NMP.g-1 (Tabela 1).

Tabela 1: Médias colimétricas mensais e anuais, expressas em NMP.g ${ }^{-1}$, de duas amostras de mexilhões analisadas entre abril de 2007 e março de 2008

\begin{tabular}{lcc}
\hline \multirow{2}{*}{ Mês } & \multicolumn{2}{c}{ Coliformes (NMP/g) } \\
\cline { 2 - 3 } & Totais & Termotolerantes \\
\hline Abril/2007 & 6,85 & $<0,18^{\star}$ \\
Maio & 6,85 & 0,55 \\
Julho & 2,31 & 1,62 \\
Agosto & 0,27 & $<0,18^{*}$ \\
Setembro & 0,64 & $<0,18^{\star}$ \\
Novembro & 160,94 & 35,74 \\
Dezembro & 0,95 & 0,19 \\
Janeiro/2008 & 7,08 & $<0,18^{\star}$ \\
Fevereiro & 54,23 & 7,92 \\
Março & 4,93 & 0,32 \\
\hline Média & 24,50 & 4,63 \\
\hline
\end{tabular}

$\left({ }^{*}\right)=$ considerado igual a zero para o cálculo da média anual.

Observou-se que as médias das concentrações de coliformes encontradas nos tecidos dos bivalves nos meses de novembro de 2007 e fevereiro de 2008 foram significativamente superiores às obtidas nos demais meses $(\mathrm{P}<0,05)$. Dentre as variáveis ambientais estudadas por Lee e Morgan (2003), a precipitação de chuvas em dias anteriores à coleta das amostras foi a que apresentou maior influência, mesmo que indiretamente, sobre a contaminação dos moluscos com bactérias de origem fecal. A precipitação pluviométrica também parece ter sido o motivo para 0 aumento das médias colimétricas da região do estudo em novembro de 2007 e fevereiro de 2008 (Pereira, 2008).
Acredita-se que a enfermidade que mais acomete os mexilhões seja o parasitismo por larvas de trematódeos da família Bucephalidae. A bucefalose vem sendo a enfermidade mais estudada, tanto devido à facilidade do diagnóstico, quanto ao número de casos de animais acometidos, inclusive gerando grandes perdas econômicas. A "doença laranja" afeta o ciclo reprodutivo dos animais, podendo reduzir ou inviabilizar sua gametogênese. Tal fato tem consequências para o setor produtivo devido à redução do número de sementes para um próximo período de cultivo (Galvão et al., 2006; Silva-Souza, 2006).

A frequência de parasitismo por bucefalídeos em mexilhões Perna perna pode estar relacionada com a contaminação bacteriológica por coliformes termotolerantes, o que é explicado devido à maior incidência dos trematódeos em mexilhões provenientes de áreas mais abrigadas e com menor ação hidrodinâmica de ondas (Galvão et al., 2006), geralmente com maior grau de contaminação de origem fecal.

No ambiente marinho, as bactérias que ficam retidas nos tecidos dos moluscos bivalves são provenientes de diferentes origens. Espécies autóctones são naturalmente residentes no ambiente aquático, como as pertencentes ao gênero Vibrio. Já as espécies alóctones estão presentes neste ambiente como resultado de contaminação externa, como aporte de efluentes domésticos com coliformes. Em uma primeira análise, a ocorrência simultânea destes dois grupos bacterianos no mar parece não ter correlação direta, principalmente devido às suas diferentes origens. Porém, alguns pesquisadores vêm salientando que a reprodução dos víbrios pode ser favorecida pela poluição orgânica de natureza fecal (Vieira et al., 2007), cuja presença pode ser constatada através das análises de coliformes termotolerantes.

É importante ressaltar a possibilidade de correlação entre a ocorrência de protozoários dos gêneros Cryptosporidium e Giardia com coliformes termotolerantes, visto que possuem a mesma origem de contaminação no ambiente marinho. Muitos autores, no entanto, questionam esta associação, uma vez que o monitoramento de bactérias indicadoras não é suficiente para garantir a sanidade do animal quanto à presença de protozoários (Leal; Franco, 2008).

Como ainda não é conhecido o grau de contaminação por coliformes que seria indicativo da ocorrência tanto de parasitismo quanto de infecções, é mais indicado proceder análises específicas para cada um dos organismos patogênicos, como Bucephalus, Vibrio, Cryptosporidium e Giardia. Apesar da relação existente entre as bactérias de origem fecal e diversos grupos de patógenos, a ausência de coliformes num determinado ambiente não significa que não possam existir os outros organismos patogênicos na mesma região.

Em pesquisa desenvolvida por Henriques et al. (2003), estes autores propõem que a contaminação bacteriológica afetaria o tempo de resistência do mexilhão Perna perna à exposição ao ar, mesmo que esta contaminação estivesse abaixo dos limites máximos permitidos para o consumo. Em se confirmando tal relação, este fato teria implicações diretas sobre a comercialização do produto que, em geral, é feita com os animais ainda vivos e expostos ao ar atmosférico. Além disso, mexilhões provenientes de regiões mais 
contaminadas por coliformes totais e fecais seriam menos resistentes a altas temperaturas (Henriques et al., 2007), a baixas salinidades (Henriques et al., 2006) e a exposição ao ar (Henriques et al., 2003), o que acarretaria maior índice de mortalidade durante seu transporte até o consumidor final. Animais que estiveram em contato com esgoto não tratado durante um prolongado período de tempo também secretam menos bisso, atrapalhando sua adesão aos costões rochosos (Moles; Hale, 2003).

A média anual de coliformes totais encontrada no presente estudo foi inferior à detectada nas pesquisas de Henriques et al. (2003; 2006; 2007). Contudo, a média de coliformes termotolerantes é ainda uma ordem de grandeza superior às relatadas por estes autores, podendo indicar maior susceptibilidade dos animais da ilha Guaíba a situações de estresse. Todavia, outros autores demonstram que os bivalves possuem em sua hemolinfa células responsáveis por inúmeros mecanismos de defesa do animal. Os hemócitos são responsáveis principalmente pelos processos de fagocitose, produção de espécies reativas de oxigênio e liberação de enzimas lisossomais. Sendo assim, sua hemolinfa possui atividade microbicida capaz de eliminar células bacterianas, influenciando diretamente sobre a capacidade de depuração desses moluscos. Tal atividade antibactericida da hemolinfa depende tanto da variedade bacteriana que entra em contato com os hemócitos quanto da integridade do sistema imunológico dos bivalves (Canesi et al., 2001; Akaishi, 2007).

Canesi et al. (2001) estudaram a interação entre a superfície celular de Escherichia coli e os hemócitos presentes na hemolinfa do mexilhão Mytilus galloprovincialis e concluíram que células de $E$. coli que possuem fímbrias do tipo 1 são mais facilmente removidas da circulação dos animais do que cepas que não possuem este apêndice. Os hemócitos parecem expressar receptores de superfície que se ligam às fímbrias, aproximando seu ataque às bactérias. Além disso, a presença da fração sérica da hemolinfa (soro) pode potencializar a interação entre as células bacterianas e os hemócitos como consequência da ação de fatores humorais de aglutinação (aglutininas).

Além dos mecanismos supracitados, as células podem ainda produzir compostos que possuem ação bactericida, como é o caso do peroxidonitrito. Entretanto, a resposta imunológica de organismos aquáticos pode ser alterada quando são expostos a esgoto sem tratamento, bloqueando sua capacidade de eliminar bactérias patogênicas presentes em seus tecidos. Experimentos demonstraram haver uma taxa de mortalidade de $100 \%$ em mexilhões da espécie $M$. edulis infectados com a bactéria Listonella anguillarium que haviam

\section{Referências}

AKAISHI, F. M. Avaliação dos efeitos tóxicos de esgoto doméstico tratado e não-tratado em bivalve marinho Mytilus edulis. 2007. 121 f. Tese. Universidade Federal do Paraná, Curitiba, 2007.

BRASIL. Ministério da Agricultura, Pecuária e Abastecimento-MAPA. Instrução Normativa n. 62, de 26 de agosto de 2003. Diário Oficial da União de 18 setembro 2003.

BRASIL. Secretaria Especial de Aquicultura e Pesca - SEAP. Instrução Normativa no 02, de 13 de fevereiro de 2007. sido expostos a esgoto doméstico in natura. A exposição ao esgoto por prolongado período de tempo apresenta uma tendência de inibir a atividade fagocítica dos hemócitos do mexilhão. Também foi verificada uma maior incidência de alterações morfofisiológicas em órgãos e tecidos, principalmente nas brânquias e glândula digestiva, em animais submetidos a este tratamento. Tais alterações são evidenciadas com exposição aguda aos contaminantes, já respostas hormonais e reprodutivas são detectadas apenas após exposições crônicas (Akaishi, 2007).

A ilha Guaíba situa-se a aproximadamente 1,6 km do continente. Esta também é a distância das moradias mais próximas e que poderiam influenciar a contaminação microbiológica das águas que a rodeiam. Porém, diante do exposto na Tabela 1, pode-se inferir que a poluição bacteriológica das águas ao redor da ilha Guaíba é leve e intermitente, ocorrendo em maiores índices apenas nos períodos posteriores a fortes chuvas.

O Brasil não possui padrões regulamentares de coliformes em moluscos bivalves in natura não consumidos crus, mas encontra-se em processo de elaboração o Programa Nacional de Controle Higiênico-Sanitário de Moluscos Bivalves, coordenado pela Secretaria Especial de Aquicultura e Pesca, que visa assegurar a sanidade dos animais e inocuidade do alimento, a partir do monitoramento bacteriológico, de ficotoxinas, metais tóxicos e pesticidas, além de implementar um sistema de rastreabilidade para os moluscos produzidos (Suplicy, 2007; Leal; Franco, 2008).

\section{Conclusões}

Os valores médios de coliformes totais e fecais presentes nos mexilhões da ilha Guaíba são baixos ao longo de todo o ano, elevando-se após períodos chuvosos. É possível que mesmo em índices baixos, os coliformes presentes sejam capazes de tornar os moluscos mais susceptíveis a fatores de estresse durante sua comercialização, dependendo da competência do sistema imune dos animais em atuar sobre as bactérias. Apesar da utilização de análises colimétricas em moluscos bivalves não ser uma ferramenta completa para classificá-los como saudáveis, pode indicar o potencial de ocorrência de grupos nocivos ao animal e à Saúde Coletiva em seus tecidos. Para um maior conhecimento sobre a qualidade do alimento é necessário ampliar esforços em estudos específicos para outros organismos e substâncias patogênicas, como bactérias dos gêneros Salmonella, Staphylococcus e Vibrio, além de vírus entéricos, protozoários, biotoxinas e metais tóxicos.

CANESI, L. PRUZZO, C.; TARSI, R. GALLO, G. Surface interations between Escherichia coli and hemocytes of the Mediterranean mussel Mytilus galloprovincialis Lam. Leading to efficient bacterial clearance. Applied and Environmental Microbiology, v. 67, n. 1, p. 464-468, 2001.

FERREIRA, V. M. Distribuição espacial, em microescala, e sazonal das microalgas potencialmente toxígenas Dinophysis spp. (Ehremberg 1839) na ilha Guaíba (município de Mangaratiba, RJ) e suas possíveis implicações no cultivo de moluscos bivalvos. 2009. 107 f. Tese (Doutorado em Ciências Veterinárias). Universidade Federal Rural do Rio de Janeiro, Seropédica, 2009. 
FOOD AND AGRICULTURE ORGANIZATION - FAO. National Aquaculture Sector Overview: Brasil. Disponível em: <http:// www.fao.org/fishery/countrysector/naso brazil/en\#tcNB0122>. Acesso em: 21 jul. 2008.

FOOD AND AGRICULTURE ORGANIZATION - FAO. Síntesis regional del desarrollo de la acuicultura 1. América Latina y el Caribe 2005. FAO Circular de Pesca, oㅜ 1017/1. Roma: FAO, 2006. 177 p.

GALVÃO, M. S. N.; HENRIQUES, M. B.; PEREIRA, O. M.; MARQUES, $H$. L. A. Ciclo reprodutivo e infestação parasitária de mexilhões Perna perna (Linnaeus, 1758). Boletim do Instituto de Pesca, São Paulo, v. 32, n. 1, p. 59-71, 2006.

HENRIQUES, M. B.; MARQUES, H. L. A.; PEREIRA, O. M. ; LOMBARDI, J. V. Resistência do mexilhão Perna perna a baixas salinidades e sua relação com a contaminação bacteriológica. Boletim do Instituto de Pesca, São Paulo, v. 32, n. 2, p. 107-114, 2006.

HENRIQUES, M. B.; PEREIRA, O. M.; MARQUES, H. L. A. Resistência do mexilhão Perna perna a altas temperaturas e sua relação com a contaminação bacteriológica. Arquivos de Ciências do Mar, Fortaleza, v. 40 , n. 1, p. 52-57, 2007.

HENRIQUES, M. B.; MARQUES, H. L. A.; LOMBARDI, J. V.; PEREIRA, O. M.; GARCIA, A. L. B. Influência da contaminação bacteriológica sobre a resistência do mexilhão Perna perna (Linnaeus, 1758) à exposição ao ar. Arquivos de Ciências do Mar, Fortaleza, v. 36, p. 95-99, 2003.

INSTITUTO BRASILEIRO DO MEIO AMBIENTE E DOS RECURSOS NATURAIS RENOVÁVEIS - IBAMA. Estatística da pesca 2006 Brasil: grandes regiões e unidades da federação. Brasília, DF: IBAMA, 2008. $174 \mathrm{p}$.

LEAL, D. A. G.; FRANCO, R. M. B. Moluscos bivalves destinados ao consumo humano como vetores de protozoários patogênicos: metodologias de detecção e normas de controle. Revista Panamericana de Infectología, v. 10, n. 4, p. 48-57, 2008.

LEE, R. J.; MORGAN, O. C. Environmental factors influencing the microbiological contamination of commercially harvested shellfish. Water Science and Technology, v. 47, n. 3, p. 65-70, 2003.

MAGALHÃES, A. R. M.; SCHAEFER, A. L. C.; FOSSARI, T. Mexilhão Perna perna (Linnaeus, 1758): nativo sim do Brasil. In: ENCONTRO BRASILEIRO DE MALACOLOGIA, 20., 2007, Rio de Janeiro. Livro de Resumos do XX EBRAM. Rio de Janeiro: Sociedade Brasileira de Malacologia, 2007, p. 237.

MOLES, A.; HALE, N. Use of physiological responses in Mytilus trossulus as integrative bioindicators of sewage pollution. Marine Pollution Bulletin, v. 46, p. 954-958, 2003.

PEREIRA, M.M.D. Avaliação Bacteriológica da Água do Mar e dos Mexilhões Perna perna (Linnaeus, 1758) cultivados na ilha Guaíba, Baía de Sepetiba, RJ. 2008. 80 f. Dissertação (Mestrado em Microbiologia Veterinária). Universidade Federal Rural do Rio de Janeiro, Seropédica, 2008.

SILVA-SOUZA, A.T. (Org.). Sanidade de Organismos Aquáticos no Brasil. Maringá: Abrapoa, 2006. p. 79-117.

SUPLICY, F. Licenciamento ambiental e regularização da maricultura. In: SEMINÁRIO ESTADUAL DE MARICULTURA, 5., 2007, Cabo Frio. Disponível em: <http://www.sebraerj.com.br>. Acesso em: 21 jul. 2008.

VIEIRA, R. H. S. F.; CASTRO, H. M. P.; REIS, C. M. F.; REIS, E. M. F.; MADRID, R. M.; HOFER, E. Aspectos Microbiológicos de Águas Estuarinas nos Estados do Rio Grande do Norte e Ceará. Arquivos de Ciências do Mar, Fortaleza, v. 40, n. 1, p. 89-95, 2007.

VIEIRA, S. Análise de variância (ANOVA). São Paulo: Atlas, 2006. $204 \mathrm{p}$. 